Article

\title{
Energy Savings in an Office Building with High WWR Using Glazing Systems Combining Thermochromic and Electrochromic Layers
}

\author{
Michaela Detsi *, Aris Manolitsis, Ioannis Atsonios, Ioannis Mandilaras ${ }^{\mathbb{D}}$ and Maria Founti $\mathbb{D}$ \\ Lab. of Heterogeneous Mixtures and Combustion Systems, School of Mechanical Engineering, \\ National Technical University of Athens, Heroon Polytechniou 9, 15780 Zografou, Greece; \\ armnlts@central.ntua.gr (A.M.); atsoniosgiannis@central.ntua.gr (I.A.); gman@central.ntua.gr (I.M.); \\ mfou@central.ntua.gr (M.F.) \\ * Correspondence: detsimichaela@mail.ntua.gr; Tel.: +30-210-772-3886
}

Received: 26 April 2020; Accepted: 5 June 2020; Published: 11 June 2020

\begin{abstract}
This paper assesses energy savings in terms of heating, cooling, and artificial lighting achieved in an office building with a high Window to Wall Ratio (WWR), located in Athens and Stockholm. Six different configurations of triple pane windows combining thermochromic, electrochromic, and low-e coatings in Insulated Glass Units (IGUs) are examined to quantify the potential of increasing energy savings in office buildings. The combination of electrochromic and thermochromic layers on the outer pane of the triple IGU, achieved an $18.5 \%$ and $8.1 \%$ reduction in annual primary energy use for Athens and Stockholm, respectively. The used switching strategy ensured the visual comfort of the employees and provided adequate daylight in both cases. It was found that in Stockholm the cooling system can be downsized considerably, achieving important cost reduction in the HVAC system. The analysis also takes into account the reduction of thermal storage in the building envelope due to the switchable windows. This reduction is beneficial in the case of Athens, but it can reduce energy savings in Stockholm. Therefore, for colder climates, it is important to increase window heat gains through the development of layers with higher g-value in the clear state and through the application of appropriate switching strategies.
\end{abstract}

Keywords: electrochromic glazing; thermochromic glazing; office building; high WWR; energy savings; heating demands; cooling demands; office lighting; EnergyPlus

\section{Introduction}

The building sector is considered to be the largest single energy consumer in Europe, absorbing approximately $40 \%$ of final energy for heating, cooling, ventilation, artificial lighting, and various appliances. Specifically, non-residential buildings are responsible for $14 \%$ of the total energy use in the EU [1]. About 75\% of buildings are still energy inefficient and greenhouse gas emissions created by building energy use are a main cause of global warming and climatic change [2]. As a result, energy conservation has become one of the main targets of energy policies and has a significant effect on the decision-making process of architectural design. In a typical residential building, heating, cooling, artificial lighting, and hot water generation make up approximately $60 \%$ of total energy use. Commercial buildings usually require less energy for heating, but present around $15 \%$ higher energy use in terms of cooling and lighting [3].

Windows constitute an integral element of the building envelope, as they offer daylight and natural ventilation, as well as a view to the building's external environment, which has been proven to spur work productivity and improve indoor comfort [4]. Natural daylight and its beneficial effects on people 
are key aspects of the design process of the building envelope's glazed area. Previous studies [5-7] have pointed out a correlation between the lack of windows in the workplace and job dissatisfaction, feelings of isolation, depression, claustrophobia, restriction, and tension. Leather et al. [8] concluded that sunlight penetration has a considerable and direct impact on job satisfaction and reduces the intention to quit. It was also deduced that a view of natural elements can offset the negative effect of occupational stress on intention to quit more effectively than residential and urban scenes. Notable research has also been conducted on the beneficial attributes of daylight for people's health. According to Zielinska-Dabkowska and Xavia [9], natural daylight drives fundamental biological processes, from circadian rhythms to sleep and mood, that are disturbed by most types of artificial lighting or even harmed by the blue-rich white light emitted from LEDs. In a review article, Lagrèze and Schaeffel [10] pointed out that limited exposure to daylight increases the risk of developing myopia by a factor of five. Beauchemin and Hays [11] and Benedetti et al. [12] observed that exposure to natural sunlight reduced the length of hospitalization of bipolar inpatients, as well as in-patients with severe and refractory depression. The effect of morning sunlight was found to be particularly beneficial [12].

In the past, architects have been hesitant to include large window areas in their constructions due to their higher thermal transmittance values compared to the opaque elements of the building envelope. In terms of energy efficiency, windows are considered to be thermally weak, as approximately $60 \%$ of the total energy loss derives from conduction, convection, and radiation through them, leading to an increase in energy use for heating or cooling [13]. Recently, building facades can be designed with a higher Window to Wall Ratio (WWR) than the code prescriptive maximum through the use of high-performance glazing systems, including dynamic switchable glazing that may or may not be used in combination with interior or exterior shading. It has been estimated that the WWR of office buildings built in Europe before 1980 is approximately 30\%, while offices that were constructed later have a WWR of $60 \%$ [14]. Modern architectural trends include office buildings with high WWRs to take advantage of the available daylight and decrease electric lighting use. At the same time, however, attention must be paid to the building's cooling energy consumption, since about $37 \%$ of it is caused by unwanted solar heat gain $[15,16]$.

Especially in the case of cooling dominated climates, the trade-off between natural daylight and excessive solar heat gain can be regulated with the use of smart switchable windows, manufactured from chromogenic materials. These materials are able to alter their optical properties in a precise and reversible way in response to an external stimulus [17]. The most popular applications in fenestration products involve mostly electrochromic (EC) and thermochromic (TC) materials.

Coloring of an electrochromic material occurs with the application of an external electric voltage of approximately $1-5$ Volts DC through the insertion and extraction of small mobile ions. Electrochromic devices consisting of both inorganic or organic layers are the most popular application of chromogenic materials, since they offer the ability of automatic control according to the user's preferences or through data selected from thermal and lighting sensors, according to lighting and HVAC desired set points [18].

Numerous energy simulation studies have been published concerning the energy saving potential of electrochromic windows. Sbar et al. [19] concluded that for building retrofit cases, the replacement of single windows with electrochromic glazing can lead to annual energy savings $\geq 45 \%$ for three U.S. cities with significantly different climatic conditions, while peak load $\mathrm{CO}_{2}$ emissions were reduced by $35 \%$ in new construction and $50 \%$ in renovation projects. The results of an energy simulation conducted by Aldawoud [20] indicated that an electrochromic glazing system presented the best energy performance, leading to significant reductions in solar heat gains for all orientations (approximately by 53-59\%), compared to conventional fixed shading devices. Through a sensitivity analysis Dussault and Gosselin [21] concluded that the integration of an electrochromic window has a considerable effect on the total energy use and peak demand, with the largest savings presented in the case of cooling. Buildings with high values of WWR displayed the highest potential for energy savings. Tavares et al. [22] also came to the conclusion that the electrochromic technology is an effective option to achieve energy savings for buildings with high cooling requirements. In terms of user performance 
and satisfaction, Jamrozik et al. [23] used, as a reference, the case of blackout shades that completely obstruct daylight and view to assess the impact of mesh shades and electrochromic windows on employees in an office space. It was deduced that the cognitive function performance (working memory and inhibition) of the workers improved for both shading types. Satisfaction with light and the overall environment improved and symptoms of eyestrain were reduced in both cases. In the case of the electrochromic windows, less visual discomfort and concentration difficulty were also reported.

Thermochromic materials alter their optical properties in accordance with the temperature of the thermochromic layer. When the temperature exceeds a critical value that is referred to as the Transition Temperature (TT), a phase change and altering of the material's crystalline structure occurs, resulting to a transition from a transparent to a translucent state. In its tinted state, the window is able to scatter incident solar radiation, especially in the Near-Infrared Region (NIR), which is mainly responsible for heat transfer. The most well-known thermochromic material is vanadium dioxide $\left(\mathrm{VO}_{2}\right)$, with a transition temperature of $68^{\circ} \mathrm{C}$ [24]. For applications in fenestration, the most desirable properties are considered to be a low transition temperature that reduces solar heat gains, a high visible transmittance that is accomplished with thin coatings and an ability to regulate significantly NIR transmittance in their colored state [13,24].

Liang et al. [13] compared the thermal and optical behavior of five thermochromic windows with different transition temperatures to standard double windows for five climatic regions in China. The results indicated that a low transition temperature is not always beneficial, since it can lead to coloring of the window during the winter months and an increase in the building's heating needs. The integration of the thermochromic windows was also found to be more suitable for warmer climates [13,24]. Through an energy simulation by means of EnergyPlus, Allen et al. [25] concluded that a thermochromic window can lead to energy savings of approximately $22 \%$ compared to a standard double window and $6 \%$ compared to a double window with a solar control low-e coating in a hot Mediterranean climate. It was also discovered that solar heat gains can be minimized by lowering the associated transition temperature range. Hoffman et al. [26] studied hypothetical, near-infrared switching, thermochromic windows for different window sizes, orientations, and climatic conditions. It was discovered that the thermochromic windows reduced occupant discomfort due to glare, while a $13.7-16.7 \%$ decrease in energy use could be achieved through large-area windows with south, east, and west orientation, in hot climates.

In the past decades, a large variety of theoretical and experimental studies concerning the energy saving potential of electrochromic or thermochromic materials in the building sector have been published. However, to the authors' knowledge, there have been no attempts to study the energy saving potential of a glazing system that includes both types of coating. The aim of this study is to provide an initial evaluation of the energy saving potential of an Insulated Glass Unit (IGU) that includes both electrochromic and thermochromic layers and to propose a suitable configuration that has the potential of maximizing energy savings. The IGUs are compared in terms of total annual primary energy use. The energy demands for heating/cooling and the electricity consumption for artificial lighting are considered. The most suitable configuration of such an IGU is determined and its energy saving potential is assessed compared to state-of-the-art window system configurations. The impact of the proposed window systems on thermal storage in the building envelope is also investigated. To take into account the effect of the climatic conditions, the energy performance of a high WWR office building equipped with different switchable window cases is examined for the Mediterranean climate of Athens, as well as the much colder climate of Stockholm. The Daylight Glare Index (DGI) in each space is calculated and used for the control of the electrochromic switching. The amount of natural daylight that is admitted though the windows and the visual comfort of the employees are evaluated. 


\section{Materials and Methods}

\subsection{The Building Model}

As discussed, the average WWR of office buildings constructed in Europe after 1980 is $60 \%$ to take advantage of high-performance glazing systems. Hence, the building model used in the current work is an office building with high WWR, located in Greece and Sweden. Office buildings hold a large share in the non-residential building stock in both countries. Specifically, in Greece office buildings constitute approximately $23 \%$ of the total non-residential building stock, while in Sweden offices account for $24 \%$ of the building stock [27]. These two countries were chosen due to the very large difference between their climatic conditions, which allows the examination of the energy performance of the various window systems in two very different cases.

A model of a five-story office building with a square $10 \mathrm{~m} \times 10 \mathrm{~m}$ layout and a usable floor area of $455 \mathrm{~m}^{2}$ was created in SketchUp. The building possesses a glass door on the southern facade and a total window opening area of $457.6 \mathrm{~m}^{2}$, while the Window to Wall Ratio is approximately $76 \%$. The building consists of peripheral office rooms and a central zone that is assumed to be an auxiliary space (corridor, stairs and elevators). The building model, depicted in Figure 1a, consists of 41 thermal zones in total. Each peripheral office room has been modeled as a separate thermal zone, while an additional thermal zone is used for the auxiliary spaces. The uses of the various spaces are presented in Figure $1 b$ with different colors. The envelope of the building consists of curtain walls with thermal break in all orientations. The bearing structure is made of concrete, while the internal walls consist of brick wall construction. The thermal transmittance values for the various elements of the building envelope are presented in Table 1.

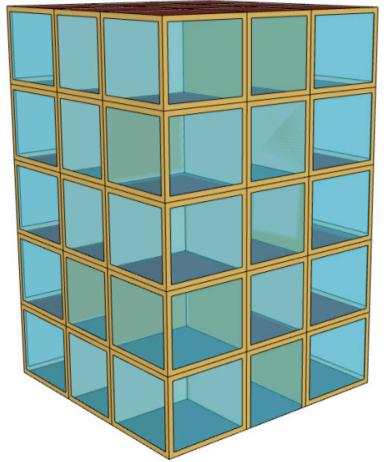

(a)

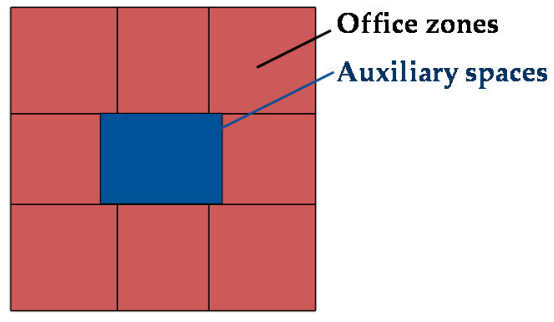

(b)

Figure 1. (a) The building model as created in SketchUp and (b) the top view of the building model.

Table 1. The U-values of the building envelope surfaces.

\begin{tabular}{cc}
\hline Surface & U-Value $\left(\mathbf{W} /\left(\mathbf{m}^{2} \mathbf{K}\right)\right)$ \\
\hline Floor & 0.4 \\
Roof & 0.4 \\
Curtain wall & 0.9 \\
Ceilings & 3.1 \\
Internal walls & 2.4 \\
\hline
\end{tabular}

Schedules for occupancy, use of lighting and electric equipment were set according to the ASHRAE 90.1 standard, as it contains detailed hourly schedules, expressed as a percentage of the maximum load, that are not included in European and national (Greek and Swedish) standards [28]. The used internal loads and schedules are presented in Table 2 and Figure 2, respectively [29,30]. The setpoint values for the thermostat used to control the HVAC systems are shown in Figure 3 [29]. 
Table 2. The building's internal thermal loads.

\begin{tabular}{ccc}
\hline Internal Thermal Load & Office Spaces & Auxiliary Spaces \\
\hline People & 0.1 people $/ \mathrm{m}^{2}$ & - \\
Artificial lighting & $16 \mathrm{~W} / \mathrm{m}^{2}$ & $3.2 \mathrm{~W} / \mathrm{m}^{2}$ \\
Electric equipment & $15 \mathrm{~W} / \mathrm{m}^{2}$ & - \\
Ventilation & $3 \mathrm{ACH}$ & - \\
Infiltration & $0.1 \mathrm{ACH}$ & $0.1 \mathrm{ACH}$ \\
\hline
\end{tabular}

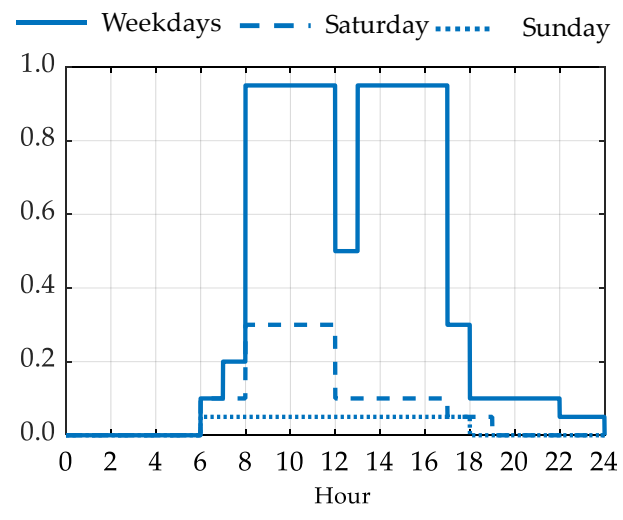

(a)

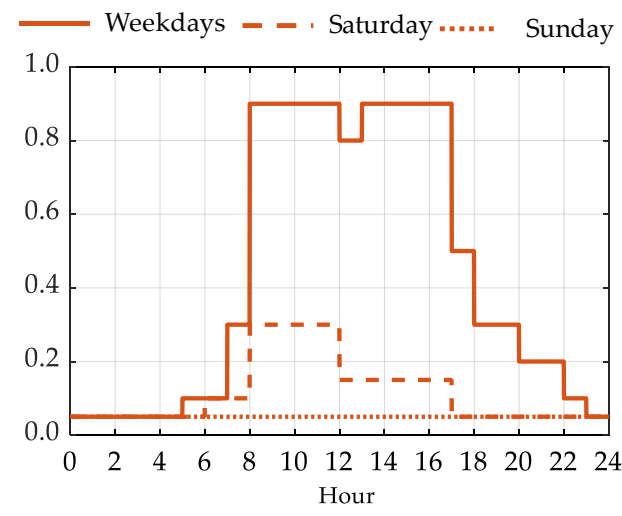

(b)

Figure 2. Schedules for (a) occupancy and (b) lighting and electric equipment use according to the ASHRAE 90.1 standard expressed as a percentage of the maximum load.

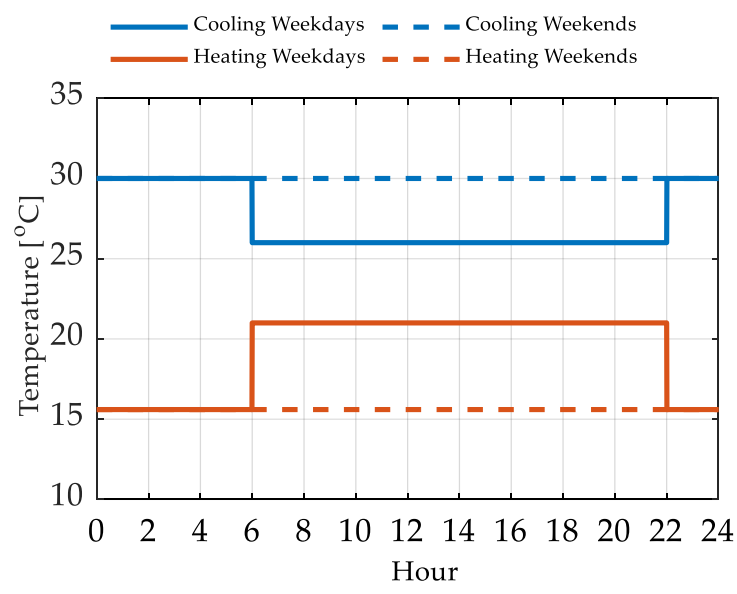

Figure 3. Thermostat setpoints for the office zones.

There are a few European standards that deal with the topic of daylight and its effect on buildings. Standard EN 15193 defines a methodology for determining the contribution of daylight in buildings, but only in the context of calculating energy requirements and electric consumption for artificial lighting. Standard EN 12464-1 specifies lighting requirements for indoor workplaces to meet the needs of visual comfort and visual performance, however it doesn't distinguish between natural light and artificial lighting. On an international level, the scope of ISO 8995-1 is comparable to EN 12464, while ISO 16817 defines a design process for high-quality indoor visual environments, in which daylight and artificial lighting systems are key aspects. In the particular study, the illuminance setpoints were set according to the requirements for office buildings presented in EN 12464-1, taking into account both natural and artificial lighting [31].

Dimmable lighting was incorporated in the model and daylighting reference points were placed in the middle of each office room. Daylight availability was calculated for each peripheral office room at a height of $0.8 \mathrm{~m}$ above the floor, which is considered to be representative for a person working in a 
seated position. In this way, the level of artificial lighting in the office rooms was controlled according to the natural daylight availability, in order to maintain a minimum illuminance of 500 lux. Dimmable lighting was not incorporated in the auxiliary spaces, as they do not have access to natural daylight. For the auxiliary spaces, an illuminance of 100 lux is considered adequate [31]. For the calculations, the visible reflectance of the interior surfaces (walls, ceilings and floors) was considered equal to 0.6 [29]. The energy simulations were carried out with the EnergyPlus software, with the use of typical EnergyPlus weather files (http://energyplus.net/).

\subsection{The Examined Window Systems}

Granqvist [32] previously recognized the potential of creating a multiple-pane configuration that includes both an electrochromic and a thermochromic coating. Specifically, in such a construction it is proposed that the electrochromic layer should be placed on the outer pane, as usual, and the thermochromic on the inner pane to ensure that its temperature is closer to the indoor temperature. Developing further this initial idea, the EU-funded project "Switch2Save" (https://cordis.europa.eu/ project/id/869929) targets active management of radiation energy transfer through glass-based building envelopes integrating electrochromic and/or thermochromic systems. Intelligent switching of such configurations could lead to significant reduction of both heating energy demand in winter and cooling energy demand in summer. Hence, the current work aims to investigate the energy saving potential of a number of IGU configurations combining thermochromic and electrochromic materials, using a triple window with low-e coatings as a reference case (case 1).

Due to the high WWR of the building, interior blinds were used in the reference case (case 1) to protect the employees from glare. For the evaluation of the energy savings, the cases of a triple thermochromic (case 2) and a triple electrochromic (case 3) window with low-e coatings are also examined. Their spectral data are presented in Figures 4 and 5.

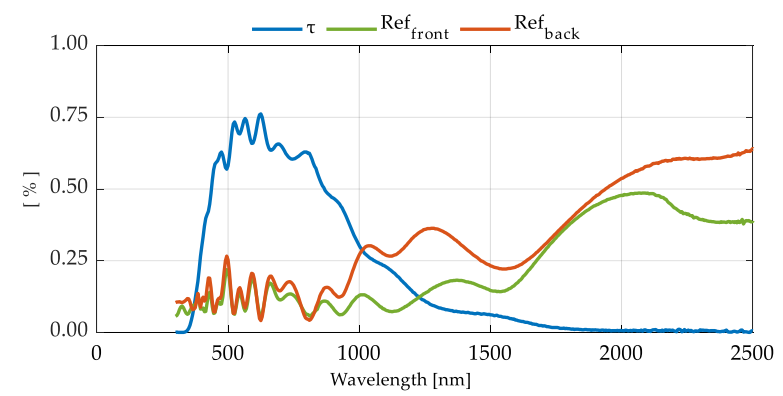

(a)

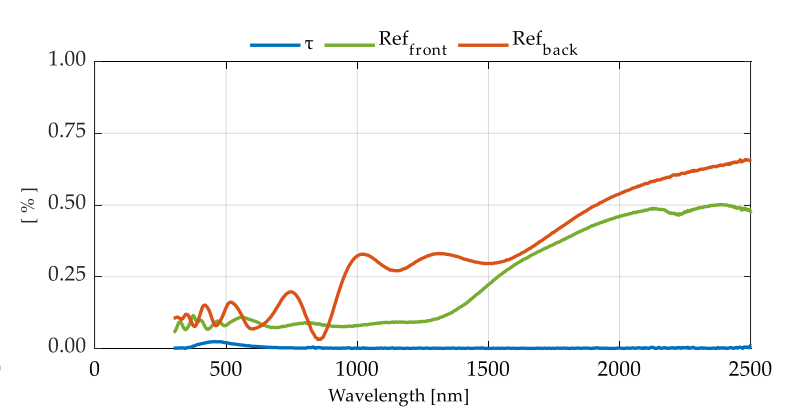

(b)

Figure 4. Spectral data of the electrochromic glass in its (a) clear and (b) tinted state.

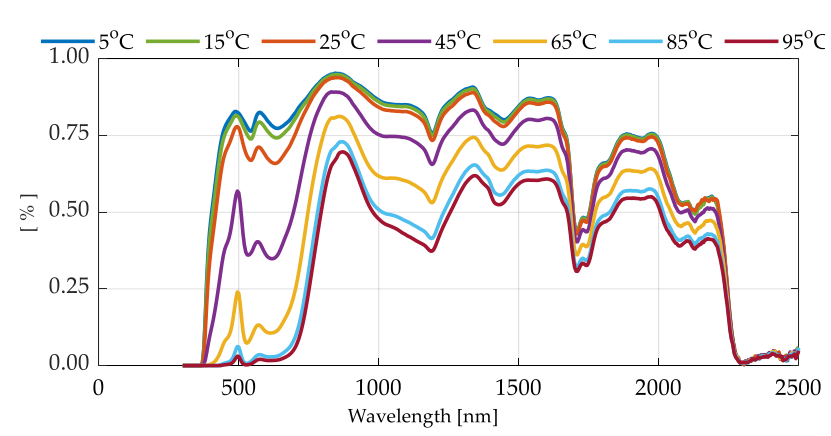

Figure 5. Transmittance of the thermochromic film for various temperatures.

Laminated configurations containing thermochromic (TC) and electrochromic (EC) or low-e coatings were created with the help of the Optics6 software [33]. The low-e coatings were added in order to ensure that the thermal transmittance values of the examined IGUs are relatively close, in order 
for the windows to be compared only according to the achieved optical modulation. The laminates were imported into WINDOW 7.7 [34] in order to calculate their thermal and optical characteristics that are presented in Table 3. All the used glass layers and films are available in the International Glazing Database (IGDB) that is maintained by the Lawrence Berkeley National Laboratory (LBNL) and is used by both software [35]. Furthermore, three configurations of windows with combined electrochromic and thermochromic properties are examined: a triple window with both an electrochromic and thermochromic layer on the outer pane (case 4), a triple window with the electrochromic layer on the outer and the thermochromic on the middle pane (case 5) and, lastly, a triple window with the electrochromic layer on the outer and the thermochromic on the inner pane (case 6).

Table 3. Thermal and optical characteristics of the different Insulated Glass Unit (IGU) configurations under investigation.

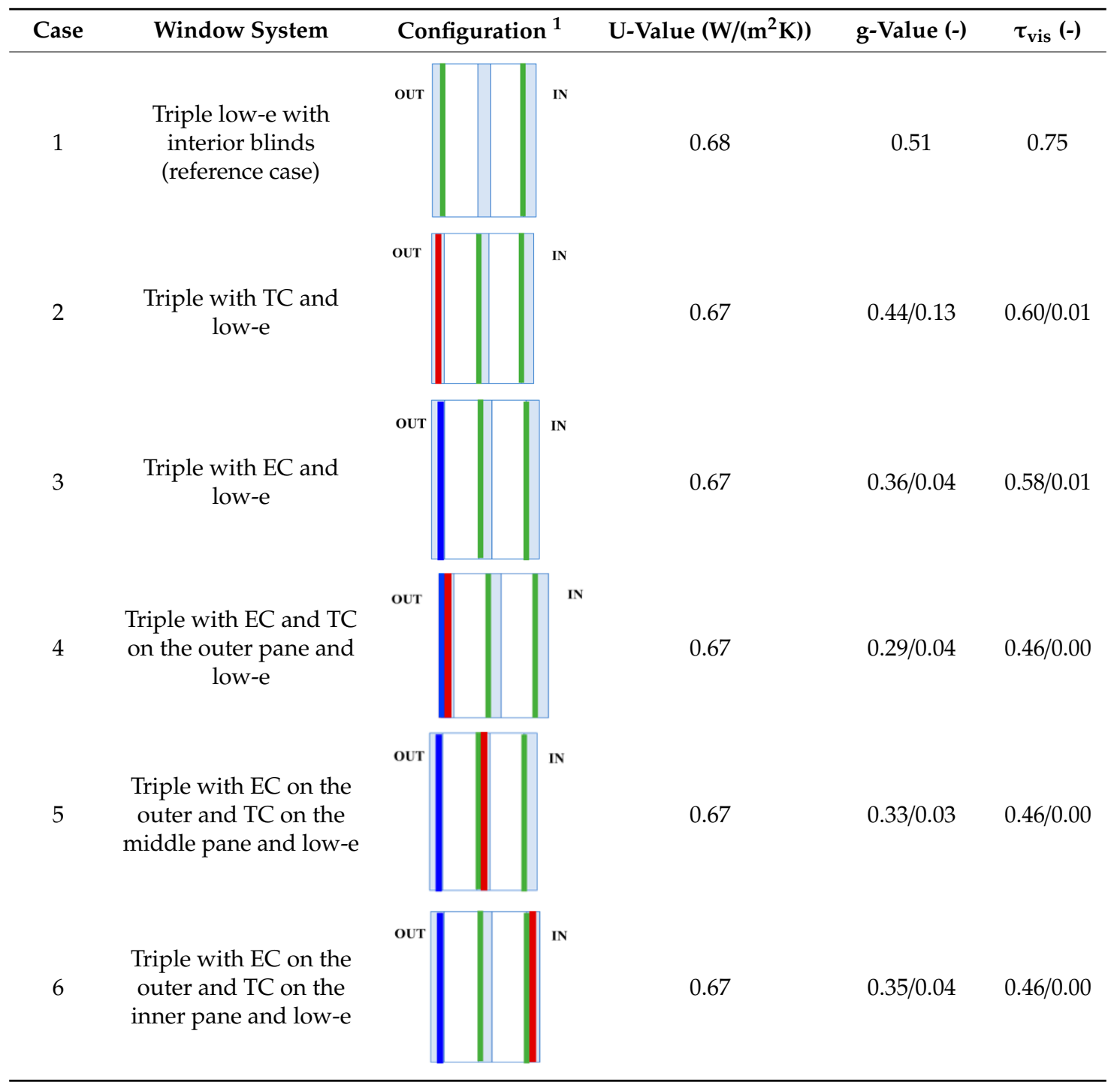

${ }^{1}$ The green line refers to a low-e coating, the red line to a thermochromic layer, and the blue line to an electrochromic layer.

For all six configurations, schematically presented in Table 3, a $14 \mathrm{~mm}$ argon gap was used to ensure a low thermal transmittance value. The thermochromic layer switches to darker states due to an increase in its temperature, while the electrochromic layer is automatically switched to its tinted state according to the control strategy described in Section 2.3. When switched to their tinted state, both thermochromic and electrochromic layers are able to reflect long-wave infrared radiation, as well 
as solar radiation in the Near-Infrared Region (NIR). The thermal transmittance (U-value), the g-value and the visible transmittance for the various window systems in their fully clear and fully tinted state are presented in Table 3. In the fully clear state, both layers are in their transparent state, while in the fully tinted state, both layers are fully tinted. For window cases $4-6$, a visible transmittance of 0.46 in the clear state can be considered relatively low. However, the combination of both electrochromic and thermochromic layers in the same window system is a new concept and a lot of research still needs to be done. Manufacturers are currently trying to create combinations of electrochromic and thermochromic materials that will result in higher values of visible transmittance in the clear state. It should also be noted that according to the indicated visible transmittance values, the windows that combine electrochromic and thermochromic layers become completely opaque in their fully tinted state. However, this state refers to a fully tinted thermochromic layer, which is achieved at a temperature of $95^{\circ} \mathrm{C}$ and is, therefore, unlikely to occur. At the same time, it is important that the examined switchable windows achieve a low enough visible light transmittance in their tinted state, as the windows need to be tinted to $2 \%$ visible transmittance or less to ensure occupant comfort in direct sunlight or during exposure to intense reflected light [19]. For cases 1-5, the visible reflectance on the inside surface of the window system is equal to 0.054 , while in case 6 , the visible reflectance is equal to 0.083 .

\subsection{The Control Strategy for the Electrochromic Layers}

In office buildings, an important factor that needs to be taken into account is the reduction of reflections and glare that could potentially bother the employees working on computers in close proximity to the windows [36]. Glare is created by incident direct solar radiation on a horizontal work plane or the vertical surface of a computer screen. Glare control is essential for buildings with high WWR values and is considered important for both examined cities. Athens is a city with high daylight availability throughout the whole year, while in the case of Northern European cities, such as Stockholm, glare can be caused due to the lower path of the sun in the sky. Switchable windows provide better glare control and thermal comfort management compared to most conventional systems. Controlling electrochromic devices to optimize comfort might require some tradeoffs with maximizing energy savings, however this is unlikely to cause a significant reduction in the achieved savings [37].

In the present study, it was decided to use a switching strategy based on glare control for the electrochromic layers to ensure the visual comfort of the employees. In other words, the electrochromic layers are expected to switch to their tinted state when the daylight zone's Daylight Glare Index (DGI) exceeds the maximum allowable DGI value, which has been set to 22 , corresponding to glare that is referred to as acceptable [38]. The threshold values for the DGI are presented in Table 4. For the calculation of the DGI, it was assumed that the employees are seated perpendicular to the windows, without facing them directly [39].

Table 4. Characterization of glare according to the Daylight Glare Index (DGI) scale.

\begin{tabular}{cc}
\hline Glare Characterization & DGI \\
\hline Intolerable & $>28$ \\
Just intolerable & 28 \\
Uncomfortable & 26 \\
Just uncomfortable & 24 \\
Acceptable & 22 \\
Just acceptable & 20 \\
Perceptible & 18 \\
Just (im)perceptible & $\leq 16$ \\
\hline
\end{tabular}

The building's total annual energy use is calculated assuming an ideal heating and cooling system that are controlled through a thermostat and supply the necessary heating or cooling energy in order to maintain the interior temperature to the desired set point values. In order to also take into consideration the energy use needed for artificial lighting, the building's heating and cooling 
needs are converted to electricity needs, assuming that both heating and cooling are accomplished through a heat pump with a COP value of 3.6 and an EER value of 3.2. This assumption was based on the fact that electricity was found to be the basic energy source of non-residential buildings for many European countries, including Greece and Sweden. Electricity is used for artificial lighting, space cooling, electrical appliances and in several cases also space heating [27]. The annual electricity needs are converted to primary energy through the conversion coefficients of 2.9 and 1.6 for electrical energy in the cases of Athens [29] and Stockholm [40], respectively. The different IGU configurations presented in Table 3 are compared to define the most suitable configuration for each climate.

\section{Results and Discussion}

\subsection{Simulation Results for Athens}

The annual energy demands obtained by the energy simulation for the model building (Figure 1) situated in the city of Athens, and for the six different IGU configurations under investigation are presented in Table 5. Due to the high daylight availability and the building's large glazing area, most of the building's heating needs are covered by the heat gains through the curtain walls. Therefore, the building's annual needs for heating are low. In the reference case (case 1, Table 3) of the triple low-e window with interior shading, it is observed that the building's annual cooling needs are significantly higher than the heating needs. Through the use of switchable glazing, a large reduction in the building's cooling needs is observed, which reaches approximately $51 \%$ in the case of the glazing system with combined electrochromic and thermochromic layers on the outer pane (case 4). This significant reduction is associated with the more sophisticated switching of the switchable windows that derives from the combination of the thermochromic and electrochromic layers. This way, many different intermediate states can be achieved, according to the temperature of the thermochromic layer and the state that the electrochromic layer is switched to. Therefore, the switchable windows provide more effective shading and reduce window heat gains and available daylight when they are switched to their tinted state. At the same time, an increase in the building's heating and lighting needs is observed for all the cases with reduced cooling needs.

Table 5. Annual energy demands for the different window cases in Athens.

\begin{tabular}{|c|c|c|c|}
\hline Case & Heating $\left(\mathrm{kWh} / \mathrm{m}^{2}\right)$ & Cooling $\left(\mathrm{kWh} / \mathrm{m}^{2}\right)$ & Lighting $\left(\mathrm{kWh} / \mathrm{m}^{2}\right)$ \\
\hline 1 & 22.87 & 114.93 & 18.07 \\
\hline 2 & 28.56 & 76.37 & 18.06 \\
\hline 3 & 38.12 & 73.21 & 18.60 \\
\hline 4 & 42.73 & 55.81 & 19.88 \\
\hline 5 & 40.33 & 68.62 & 19.86 \\
\hline 6 & 37.33 & 75.48 & 19.07 \\
\hline
\end{tabular}

As shown in Figure 6, all the examined switchable window configurations lead to significant reductions in the building's total annual primary energy consumption. The best behavior in terms of energy efficiency, indicating $18.5 \%$ reduction in annual primary energy use, is observed for case 4 , where the electrochromic and thermochromic layers are combined on the outer pane of the glazing system, indicating that this configuration and switching strategy could be useful to further increase energy savings, especially for buildings with large window areas in warm climates. The other two configurations (case 5 and case 6) that include both electrochromic and thermochromic layers also display significant energy savings compared to the reference case (case 1). Specifically, the window system with the electrochromic layer on the outer pane and the thermochromic on the middle pane (case 5) leads to $13.0 \%$ reduction in total annual primary energy use, while the glazing system with the electrochromic layer on the outer and the thermochromic on the inner pane (case 6) leads to $12.1 \%$ reduction in primary energy use. 


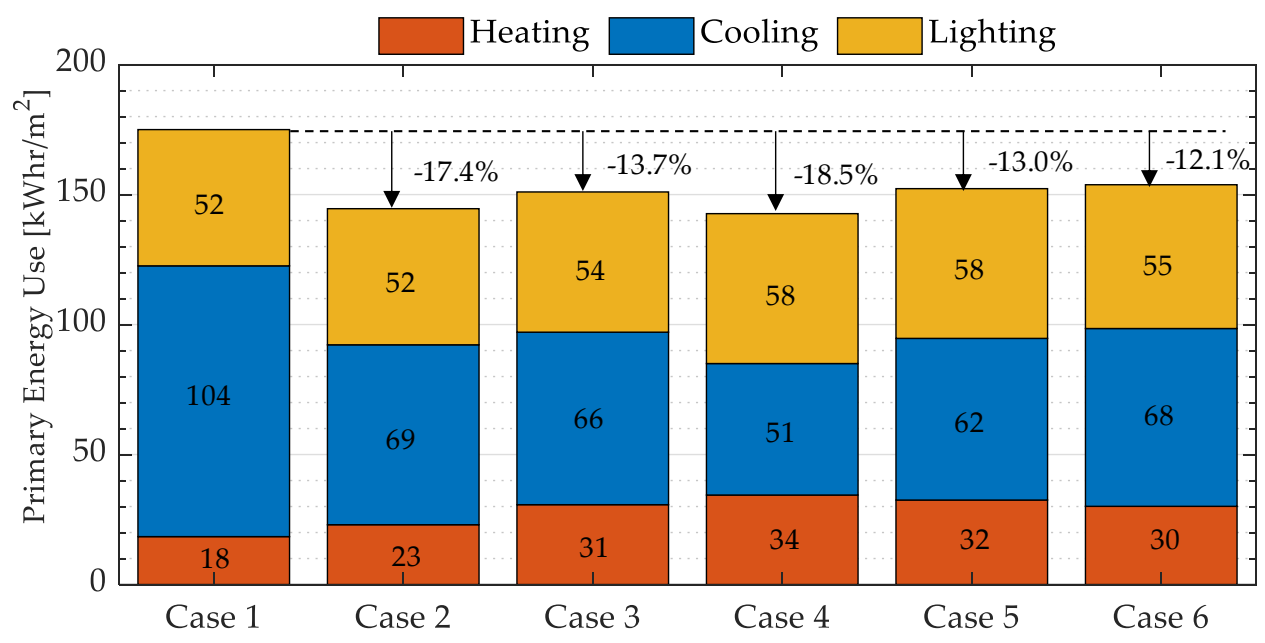

Figure 6. Total annual primary energy use for the various window system cases in Athens.

The differences in the results mentioned above are associated with the position of the thermochromic layer in the window systems that contain both electrochromic and thermochromic materials (cases 4-6). Since the thermochromic layer switches to darker states with an increase of its temperature, the placement of the thermochromic layer on the outer pane of the window system increases the effect of the climatic conditions on its behavior. Specifically in the case of Athens, which is characterized by high daylight availability, mild winters and hot summers, the temperature of the thermochromic layer rises due to the external temperature and the significant solar heat gains. As a result, window case 4 , that combines both chromogenic layers on the outer pane, switches to darker states compared to window cases 5 and 6 under the same climatic conditions, due to the higher temperature of the thermochromic layer. As the position of the thermochromic layer is transferred towards the interior space of the building, the temperature of the layer is less affected by the environmental conditions. At the same time, the thermochromic layer is influenced by the indoor environment and the building's heating and cooling systems that maintain the temperature of the space within a specified range to ensure thermal comfort.

The control strategy used for the electrochromic layers prioritized visual comfort over maximizing energy savings. However, with the combination of both layers, window system 4 managed a large reduction in the building's cooling demands and improved significantly its energy performance compared to the reference case. While the other two cases of window systems with combined electrochromic and thermochromic layers (cases 5 and 6) did not manage to outperform the triple thermochromic and triple electrochromic window, it can be anticipated that modification of the electrochromic and thermochromic film's spectral and transmissive characteristics to match the switching strategy requirements, could result in important improvement in energy savings.

Figure 7 further analyses the effect of the switchable windows on the building's energy needs by comparing the window system of case 4 , that presented the best annual energy performance, to the reference case (case 1). Since the building's cooling demands are considerably higher than for heating in Athens, an office zone with southward orientation was examined for a warm summer day. In Figure 7a, the solid lines refer to the net transmitted energy through the window for each case, the dashed lines refer to the thermal storage that is achieved in the walls of the zone and the dotted lines present the cooling energy required for each case. It can be observed that the window system of case 4 manages to reduce the total energy transfer through the zone window by $57 \%$, while peak energy gains through the window are reduced by $64 \%$. Due to the increased window heat gains in the reference case, more energy is stored in the zone envelope during the daytime and discharged during the night. As can be seen in Figure $7 \mathrm{~b}$, this results to a higher indoor temperature for the reference case during the night, when the outdoor temperature is low. On the other hand, the switchable window of case 4 reduces the thermal storage in the zone's envelope during the day resulting to a lower indoor 
temperature during the night. In Figure 7a, it is also shown that, even though the cooling system is active during the same time period for both cases, the switchable window requires $25 \%$ lower cooling energy. When the cooling system is turned off, the indoor temperature in window case 4 is $1.5^{\circ} \mathrm{C}$ lower.

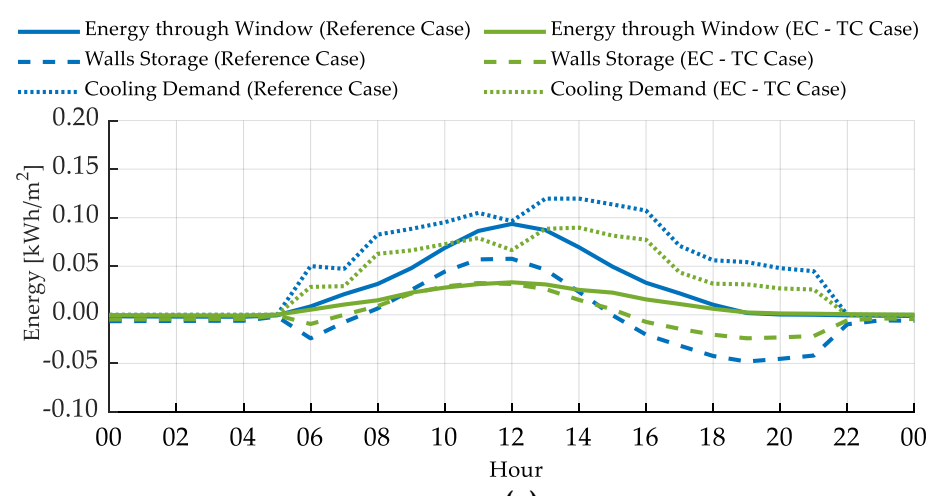

(a)

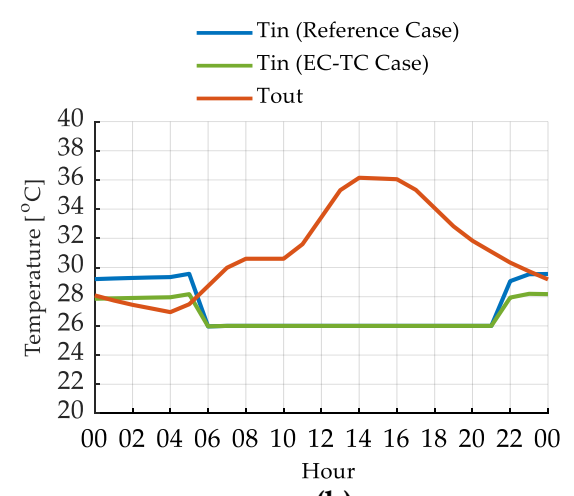

(b)

Figure 7. (a) Energy balance and (b) distribution of the interior and exterior temperature in an office zone with south orientation, on a warm summer day in Athens, for window systems 1 and 4 .

Since the switching strategy of the electrochromic layers took into account the visual comfort of the employees, the daylight availability in an office space and the possibility of glare were also examined. Figures 8 and 9 present the annual daylight availability and the calculated DGI for window system 4, in an office zone with orientation towards the south. Overall, it was deduced that window system 4 was able to admit approximately $78 \%$ of the natural daylight that would be transmitted in the space for the reference case without the use of blinds. From October to the middle of March, the entrance of natural daylight in the zone is usually blocked for approximately $1.5 \mathrm{~h}$ (from 14:00 to 15:30) and rarely for up to $3 \mathrm{~h}$ (from 13:30 to 16:30) due to the switching of the electrochromic layer, in order to protect the employees from glare. For the rest of the occupied hours, daylight availability is high and exceeds the value of 500 lux, that is considered necessary for offices. From the middle of March to June, the illuminance provided by natural daylight is also high during most days. Daylight availability is only reduced on warmer, sunny days due to the tinting of the thermochromic layer. During July and August, a large reduction in the daylight transmitted through the windows can be observed, due to the high values of ambient temperatures and solar radiation that cause the thermochromic layer to switch to darker states. Even though a small portion of natural daylight is admitted through the space during the summer, this behavior is considered beneficial from a perspective of energy performance, since the space is protected from overheating and the building's cooling needs are significantly reduced. The largest reduction in daylight availability is presented for the month of September, when the electrochromic layer usually needs to remain tinted for $4-5 \mathrm{~h}$ to block unwanted glare. Since the ambient temperatures are still quite high during this month, the thermochromic layer is also tinted for the rest of the occupied hours, allowing only a relatively small portion of daylight to enter the space and reducing the need for cooling. Overall, sufficient daylight availability is ensured for the occupied hours from October to June. In terms of visual comfort, as can be seen in Figure 9, the DGI is maintained sufficiently low throughout the whole year. Therefore, it can be concluded that the used control strategy is able to effectively protect the employees from discomfort glare. 


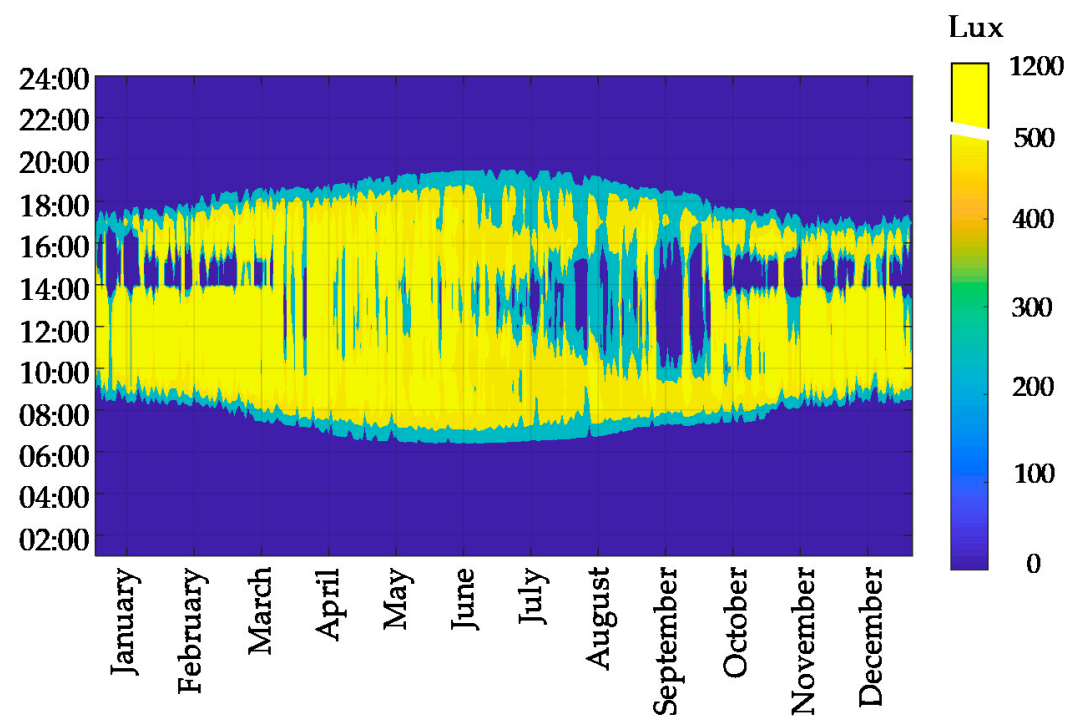

Figure 8. Annual daylight availability in an office zone with south orientation in Athens.

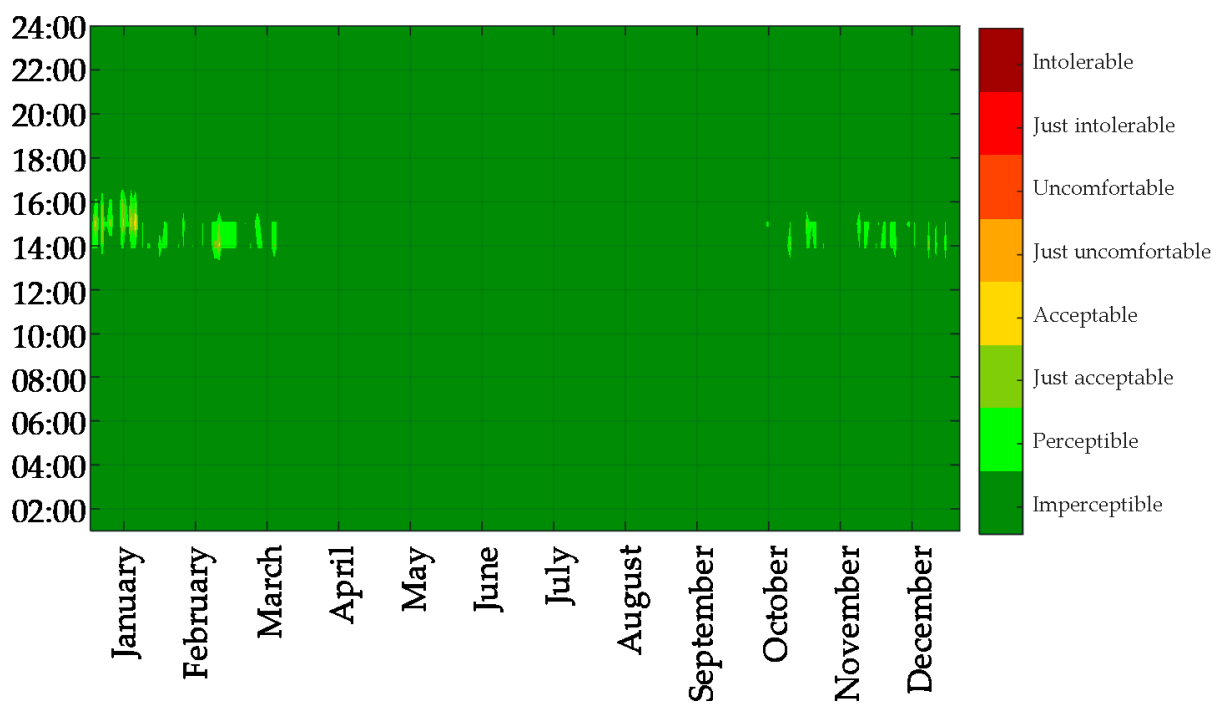

Figure 9. Annual DGI values in an office zone with south orientation in Athens.

\subsection{Simulation Results for Stockholm}

The simulation results regarding the energy needs for the same building model located in the city of Stockholm are presented in Table 6. As expected, for the much colder climate of Stockholm, the heating needs of the building are significantly higher. However, due to the heat gains from the building's large window area, it is observed that without the use of switchable glazing significant cooling would also be required. As expected, the use of switchable glazing leads to a significant reduction in cooling loads with a simultaneous increase in terms of heating and artificial lighting.

Table 6. Annual energy demands for the different window cases in Stockholm.

\begin{tabular}{|c|c|c|c|}
\hline Case & Heating $\left(\mathrm{kWh} / \mathrm{m}^{2}\right)$ & Cooling $\left(\mathrm{kWh} / \mathrm{m}^{2}\right)$ & Lighting $\left(\mathrm{kWh} / \mathrm{m}^{2}\right)$ \\
\hline 1 & 85.97 & 32.72 & 21.15 \\
\hline 2 & 89.42 & 15.46 & 21.33 \\
\hline 3 & 97.84 & 7.28 & 21.77 \\
\hline 4 & 99.48 & 2.25 & 22.42 \\
\hline 5 & 99.86 & 5.19 & 22.58 \\
\hline 6 & 96.66 & 8.21 & 22.40 \\
\hline
\end{tabular}


Comparing the annual primary energy use for the same building located in Athens (Figure 6) and Stockholm (Figure 10) it is clearly seen that the total annual primary energy savings, are ca. $40-50 \%$ less for the cold climate. Similarly to the Athens case, the window system that combines the electrochromic and thermochromic layers on the outer pane (case 4) displays the highest energy savings, with $8.1 \%$ reduction in annual primary energy use, followed by the triple thermochromic (case 2) and electrochromic (case 3) windows that reduce primary energy demand by $7.7 \%$ and $7.3 \%$ respectively. Window cases 5 and 6 present the lowest energy savings, with $6.0 \%$ and $6.2 \%$ decrease in annual primary energy use respectively. However, the difference in primary energy use for cases 5 and 6 is relatively small compared to the existing switchable window cases (cases 2 and 3). Therefore, similarly to the Athens case, increased energy savings could be anticipated for cases 5 and 6 through optimization of the film properties and control strategy.

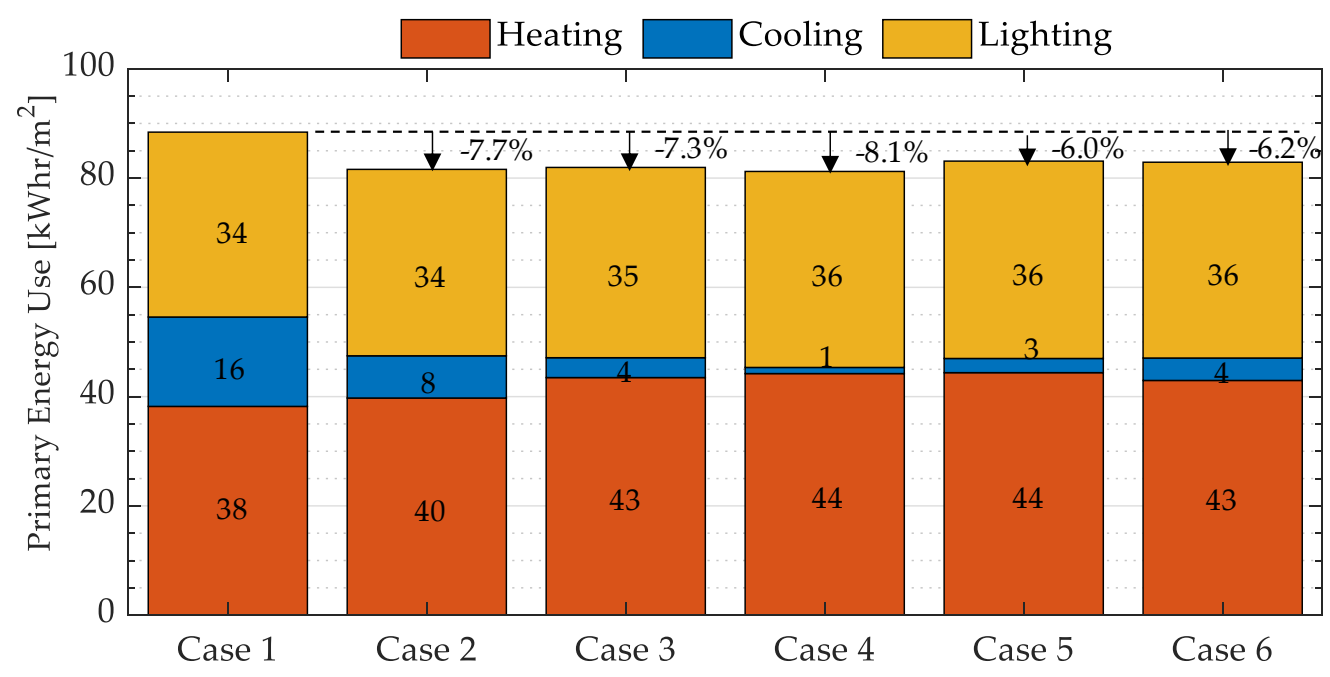

Figure 10. Total annual primary energy use for the various window system cases in Stockholm.

An additional important advantage of window system 4 is that it leads to a large reduction (ca. 93\%) of the building's cooling needs. Therefore, through the use of optimized switchable window systems that combine an electrochromic and a thermochromic layer on the outer pane, the building's cooling demands could be drastically reduced and significant cost reduction could be achieved in the HVAC equipment.

In terms of cooling, the behavior of the window systems with both electrochromic and thermochromic layers (cases 4,5, and 6) is similar to the case of Athens and a greater reduction in cooling needs is observed when the thermochromic layer is placed closer to the external environment. However, during the heating period, the behavior of the window systems is more complicated due to the very low ambient temperatures. In this case, when the thermochromic layer is placed closer to the external environment, solar heat gains are unable to cause a significant increase in the layer's temperature due to the low temperature of the ambient air. Therefore, placing the thermochromic layer on the middle pane, where it is less affected by the ambient temperature, leads to a higher temperature of the layer and switching to a darker state, which increases the building's needs for heating and artificial lighting.

In Stockholm, the model building's heating needs are more significant than its cooling needs. Therefore, the hourly energy balance and interior/exterior temperatures were examined in the same office zone as in the Athens case, for a representative cold winter day. Figure 11, indicates that, even though the case 4 window has the best annual energy performance, it does not facilitate thermal storage in the case of Stockholm. Specifically, it reduces peak energy gains through the window by $69 \%$ and reduces energy storage in the zone envelope. As a result, the indoor temperature during the 
night is lower compared to the reference case. The heating system is active for more hours and when it is turned off, the indoor temperature is lower by $1.2{ }^{\circ} \mathrm{C}$ compared to the reference case.

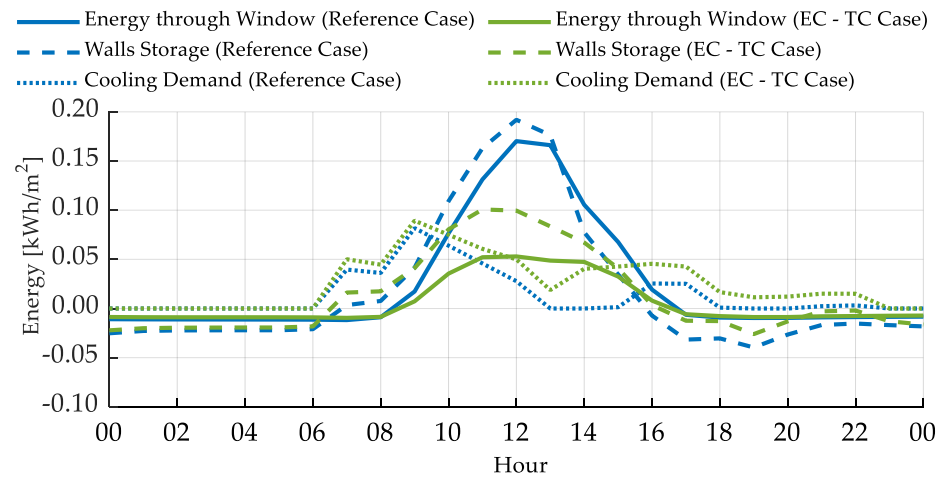

(a)

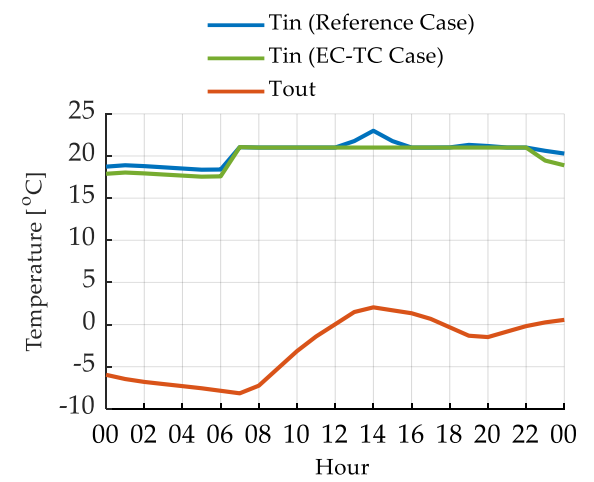

(b)

Figure 11. (a) Energy balance and (b) distribution of the interior and exterior temperature in an office zone with south orientation, on a cold winter day in Stockholm, for window systems 1 and 4 .

The main goal of using switchable windows with chromogenic materials is to reduce the building's cooling needs and to ensure the visual comfort of the employees throughout the year. The results of the study indicate that in order for this technology to be useful in countries with cold climatic conditions, it is important to increase the heat gain through the window during the day by increasing its g-value in the clear state. At the same time, a high value of visible transmittance in the clear state will allow more daylight to enter the space for the office workers visual needs. This way, it will be possible to take better advantage of the limited daylight availability during the winter months, while maintaining visual comfort and significantly reducing cooling needs during the summer months. In addition, a more sophisticated control strategy that facilitates thermal storage in the building envelope during the heating period could improve the energy performance of the window systems for heating dominated regions. Appropriate zoning strategies in terms of artificial lighting can also be utilized to ensure uniform lighting conditions when the windows are switched to a tinted state. For buildings with large window areas, zoning can also be applied to the switchable windows, by programming the windows to operate in customized zones, in order to create a more flexible system and optimize the trade-off between energy performance and comfort.

The annual daylight availability and DGI values for window system 4, in an office zone with orientation towards the south are presented for the case of Stockholm in Figures 12 and 13, respectively. For the months August to May, daylight admission in the space is blocked for approximately up to $1.5 \mathrm{~h}$ (from 13:00 to 14:30 or from 14:00 to 15:30) due to the tinting of the electrochromic layer that protects the employees from glare. For the rest of the occupied hours, the interior illuminance that derives from daylight is high and exceeds the 500 lux value that must be maintained in the office rooms. During the rest of the year, daylight availability remains high in the office zone with the exception of days with higher ambient temperature or solar radiation that cause the tinting of the thermochromic layer to its darker states. During these days, the reduction in daylight availability and the resultant need for artificial lighting are compensated by the decrease in the building's cooling demands. When compared to the transmitted daylight for the window system of the reference case, without the use of interior blinds, it was found that window system 4 allowed the admission of approximately $75 \%$ of natural daylight throughout the year. Overall, it can be observed that sufficient daylight availability is achieved for the occupied hours throughout the whole year. Similarly to the case of Athens, the visual comfort of the employees is ensured throughout the year and the DGI values are maintained sufficiently low. 


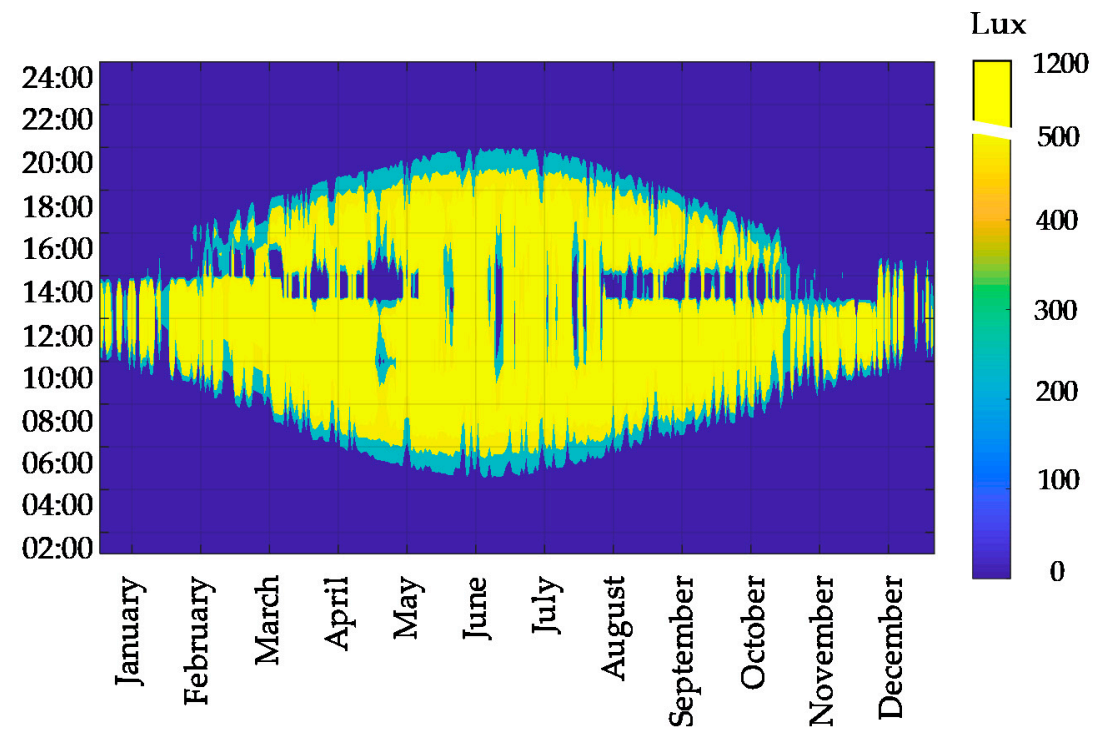

Figure 12. Annual daylight availability in an office zone with south orientation in Stockholm.

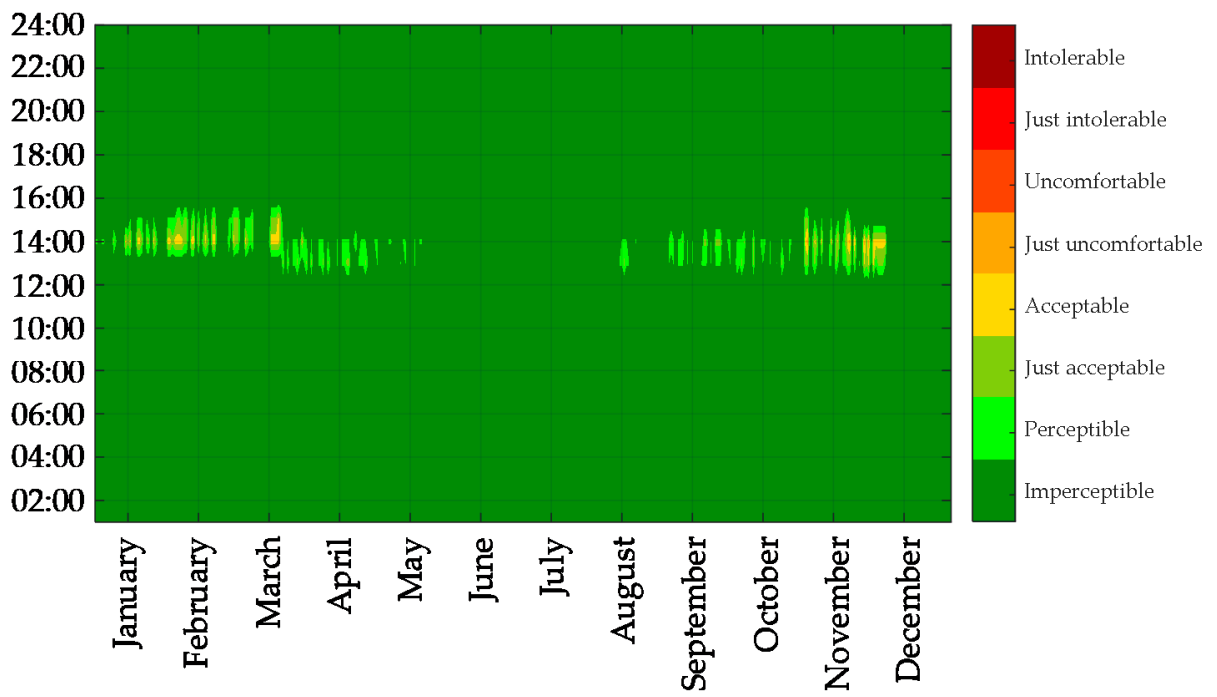

Figure 13. Annual DGI values in an office zone with south orientation in Stockholm.

\section{Conclusions}

The purpose of this study was to explore the energy saving potential of Insulated Glass Units that combine electrochromic and thermochromic materials in a modern office building with a high WWR, for two cities with significantly different climatic conditions: Athens and Stockholm. The examined window systems were created with the help of Optics6 and WINDOW 7.7 software, using glass layers and films from the IGDB Database, while priority was given to glare control during the electrochromic switching.

Energy simulation results for both locations showed that the overall highest energy savings were accomplished when the electrochromic and thermochromic layers were combined on the outer pane of the triple IGU configuration, due to the combined behavior of the two layers. A reduction of $18.5 \%$ and $8.1 \%$ in annual primary energy use was achieved for Athens and Stockholm, respectively. In the case of Stockholm, it was also concluded that the use of optimized window systems with such configuration can downsize significantly the building's cooling systems and, thus, achieve important cost reduction in the HVAC equipment. The other two examined configurations, that combined electrochromic with thermochromic films in different positions, displayed slightly lower performance compared to the triple thermochromic and triple electrochromic window. 
The use of switchable windows reduced thermal storage in the building envelope for both city cases. While, this reduction is beneficial for a cooling dominated climate, in heating dominated climates it can reduce the achieved energy savings. Therefore, especially in the case of switchable windows that combine electrochromic and thermochromic coatings in colder climates, it is important to increase heat gains through the windows by developing layers with increased g-value in the clear state and appropriate switching strategies. Visual comfort can also be maintained with a high value of visible transmittance in the clear state and appropriate zoning strategies.

In terms of visual comfort, it was found that the employees were effectively protected from discomfort glare in the case of window system 4 , since the DGI values in both cities were adequately low for the whole year. In Athens, daylight availability in an office zone with south orientation was deemed sufficient from October to June. During the summer months, the decrease in the transmitted daylight through the switchable windows was considered acceptable, due to the large reduction in the building's cooling demands. In Stockholm, it was found that sufficient daylight is transmitted through the window systems for the whole year, while the reduction of daylight admission during the summer months improved the building's energy performance by reducing its cooling needs.

As the combination of both electrochromic and thermochromic layers in the same window system is a new concept that has not yet been extensively investigated, this study necessarily made a few assumptions. Firstly, the chromogenic glass layers and films, that were used for the creation of the window systems, were derived from the IGDB Database, based on commercially available products, and were then combined with the help of the Optics6 software. Therefore, the used materials had not been specifically designed to coexist and function together in the same window system. This sets an upper limit to the energy savings that can be achieved, as the combination of the used layers has not been optimized and is, therefore, unable to take full advantage of each separate technology. In addition, since there are currently no commercially available products or prototypes that combine electrochromic and thermochromic materials, there is no information on the potential cost of this proposed technology. There are also some limitations regarding the used building model, since it does not take into account potential shading effects due to surrounding buildings that could reduce the impact of daylight and increase the building's artificial lighting demands.

Overall, it is concluded that the combination of both thermochromic and electrochromic coatings in an IGU is a promising and challenging new concept that has the potential to increase energy savings in the building sector. Future research on this topic should examine optimized combinations of electrochromic and thermochromic materials in window systems and their effect on building energy consumption, as well as the visual comfort of the occupants. More sophisticated switching strategies for these window systems should also be analyzed, taking into account facade orientation, daylight availability and climatic conditions. After the development of the first prototypes of window systems with combined electrochromic and thermochromic materials, a technoeconomic analysis would also be of interest. This analysis should take into account all the costs involved, as well as the savings due to the lack of need for additional shading devices and the downsizing of the necessary HVAC equipment. Through further research on the appropriate combination of thermochromic and electrochromic coatings, optimization of this technology, and development of advanced switching protocols, higher energy savings could be expected.

Author Contributions: Conceptualization, M.D., A.M., I.A., I.M., and M.F.; methodology, M.D., A.M., I.A., and I.M.; software, M.D. and A.M.; validation, I.A. and I.M.; formal analysis, M.D., A.M., and I.A.; investigation, M.D., A.M., and I.A.; resources, M.F.; data curation, M.D. and M.F.; writing-original draft preparation, M.D. and A.M.; writing-review and editing, M.D., A.M., I.A., I.M., and M.F.; visualization, M.D. and I.A.; supervision, M.F.; project administration M.F.; funding acquisition, M.F. All authors have read and agreed to the published version of the manuscript.

Funding: This research has received funding from the European Union's Horizon 2020 research and innovation programme under grant agreement n 869929, project Switch2save. 
Acknowledgments: The authors gratefully acknowledge the technical collaboration with the consortium of the EC "Switch2Save: Lightweight switchable smart solutions for energy saving large windows and glass" project, (https://www.switch2save.eu).

Conflicts of Interest: The authors declare no conflict of interest.

\section{References}

1. Eurostat. Simplified Energy Balances-Annual Data; Last update: 08-06-2017; Eurostat: Brussels, Belgium, 2017.

2. European Commission. Commission Welcomes Final Vote on Energy Performance of Buildings; European Commission: Brussels, Belgium, 2018.

3. U.S. Department of Energy. Energy Efficiency Trends in Residential and Commercial Buildings; U.S. Department of Energy: Washington, DC, USA, 2008.

4. Ochoa, C.E.; Aries, M.B.C.; van Loenen, E.J.; Hensen, J.L.M. Considerations on design optimization criteria for windows providing low energy consumption and high visual comfort. Appl. Energy 2012, 95, 238-245. [CrossRef]

5. Finnegan, M.C.; Solomon, L.Z. Work attitudes in windowed vs. windowless environments. J. Soc. Psychol. 1981, 115, 291-292. [CrossRef]

6. Ruys, T. Windowless Offices; University of Washington: Seattle, WA, USA, 1970.

7. Sundstrom, E. Work Places: The Psychology of the Physical Environment in Offices and Factories; Cambridge University Press: New York, NY, USA, 1986.

8. Leather, P.; Pyrgas, M.; Beale, D.; Lawrence, C. Windows in the Workplace: Sunlight, View, and Occupational Stress. Environ. Behav. 1998, 30, 739-762. [CrossRef]

9. Zielinska-Dabkowska, K.M.; Xavia, K. Protect Our Right to Light. Nature 2019, 568, 451-453. [CrossRef] [PubMed]

10. Lagrèze, W.A.; Schaeffel, F. Preventing Myopia. Dtsch. Arztebl. Int. 2017, 114, 575-580. [CrossRef]

11. Beauchemin, K.M.; Hays, P. Sunny hospital rooms expedite recovery from severe and refractory depressions. J. Affect. Disord. 1996, 40, 49-51. [CrossRef]

12. Benedetti, F.; Colombo, C.; Barbini, B.; Campori, E.; Smeraldi, E. Morning sunlight reduces length of hospitalization in bipolar depression. J. Affect. Disord. 2001, 62, 221-223. [CrossRef]

13. Liang, R.; Sun, Y.; Aburas, M.; Wilson, R.; Wu, Y. Evaluation of the thermal and optical performance of thermochromic windows for office buildings in China. Energy Build. 2018, 176, 216-231. [CrossRef]

14. Birchall, S.; Wallis, I.; Churcher, D.; Pezzutto, S.; Fedrizzi, R.; Causse, E. Survey on the Energy Needs and Architectural Features of the EU Building Stock; EC FP7 project iNSPiRe; BSRIA: Bracknell, UK, 2014; Available online: https://cordis.europa.eu/project/id/314461/reporting (accessed on 1 March 2020).

15. Balaras, C.A.; Droutsa, K.; Dascalaki, E.; Kontoyiannidis, S. Heating energy consumption and resulting environmental impact of European apartment buildings. Energy Build. 2005, 37, 429-442. [CrossRef]

16. Reilly, S.; Hawthorne, W. The impact of windows on residential energy use. ASHRAE Trans. 1998, 104, 791-798.

17. Papaefthimiou, S. Chromogenic technologies: Towards the realization of smart electrochromic glazing for energy-saving applications in buildings. Adv. Build. Energy Res. 2010, 4, 77-126. [CrossRef]

18. DeForest, N.; Shehabi, A.; Selkowitz, S.; Milliron, D.J. A comparative energy analysis of three electrochromic glazing technologies in commercial and residential buildings. Appl. Energy 2017, 192, 95-109. [CrossRef]

19. Sbar, N.L.; Podbelski, L.; Yang, H.M.; Pease, B. Electrochromic dynamic windows for office buildings. Int. J. Sustain. Built Environ. 2012, 1, 125-139. [CrossRef]

20. Aldawoud, A. Conventional fixed shading devices in comparison to an electrochromic glazing system in hot, dry climate. Energy Build. 2013, 59, 104-110. [CrossRef]

21. Dussault, J.-M.; Gosselin, L. Office buildings with electrochromic windows: A sensitivity analysis of design parameters on energy performance, and thermal and visual comfort. Energy Build. 2017, 153, 50-62. [CrossRef]

22. Tavares, P.; Bernardo, H.; Gaspar, A.; Martins, A. Control criteria of electrochromic glasses for energy savings in mediterranean buildings refurbishment. Sol. Energy 2016, 134, 236-250. [CrossRef] 
23. Jamrozik, A.; Clements, N.; Hasan, S.S.; Zhao, J.; Zhang, R.; Campanella, C.; Loftness, V.; Porter, P.; Ly, S.; Wang, S.; et al. Access to daylight and view in an office improves cognitive performance and satisfaction and reduces eyestrain: A controlled crossover study. Build. Environ. 2019, 165, 106379. [CrossRef]

24. Saeli, M.; Piccirillo, C.; Parkin, I.P.; Binions, R.; Ridley, I. Energy modelling studies of thermochromic glazing. Energy Build. 2010, 42, 1666-1673. [CrossRef]

25. Allen, K.; Connelly, K.; Rutherford, P.; Wu, Y. Smart windows-Dynamic control of building energy performance. Energy Build. 2017, 139, 535-546. [CrossRef]

26. Hoffmann, S.; Lee, E.S.; Clavero, C. Examination of the technical potential of near-infrared switching thermochromic windows for commercial building applications. Sol. Energy Mater. Sol. Cells 2014, 123, 65-80. [CrossRef]

27. EU Building Stock Observatory. Available online: https://ec.europa.eu/energy/en/topics/energy-efficiency/ energy-performance-of-buildings/eu-bso (accessed on 1 March 2020).

28. ANSI/ASHRAE/IESNA. Standard 90.1-2016; US Department of Energy, Building Energy Codes Program: Washington, DC, USA. Available online: https://www.ashrae.org/ (accessed on 1 March 2020).

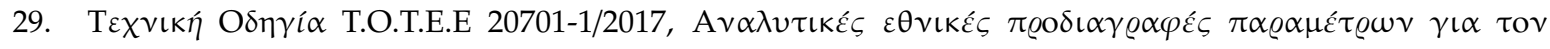

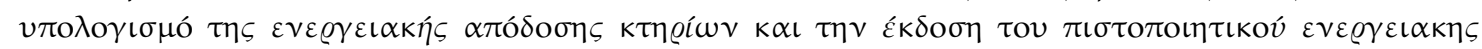
$\alpha \pi \delta$ óon $\varsigma$ (Hellenic Directive, Detailed national parameter specifications for the calculation of the building energy performance and issuing of the energy performance certificate, Technical Chamber of Greece: Athens, September 2017). Available online: http://portal.tee.gr/ (accessed on 1 March 2020).

30. ANSI/ASHRAE. Standard 62.1-2019: Ventilation for Acceptable Indoor Air Quality; American Society of Heating, Refrigerating and Air-Conditioning Engineers: Atlanta, GA, USA, 2013; Available online: https: //www.ashrae.org/ (accessed on 1 March 2020).

31. EN 12464-1:2011. Light and Lighting_Lighting of Work Places—Part 1: Indoor Work Places; BSI: London, UK, 2011; Available online: https://standards.cen.eu/ (accessed on 1 March 2020).

32. Granqvist, C.G. Oxide electrochromics: An introduction to devices and materials. Sol. Energy Mater. Sol. Cells 2012, 99, 1-13. [CrossRef]

33. Optics, 6; LBNL: Berkeley, CA, USA. Available online: https://windows.lbl.gov/software/optics (accessed on 20 March 2020).

34. WINDOW, 7.7; LBNL: Berkeley, CA, USA. Available online: https://windows.lbl.gov/software/window (accessed on 20 March 2020).

35. LBNL, Berkeley, CA, USA. Available online: https://windows.lbl.gov (accessed on 20 March 2020).

36. Lee, E.S.; Dibartolomeo, D.L.; Klems, J.H.; Yazdanian, M.; Selkowitz, S.E. Monitored energy performance of electrochromic windows controlled for daylight and visual comfort. In Proceedings of the ASHRAE 2006 Summer Meeting, Quebec City, QC, Canada, 24-28 June 2006; ASHRAE Transactions: Atlanta, GA, USA; pp. 122-141.

37. Selkowitz, S.E.; Robin, M.; Lee, E.S.; Sullivan, R.; Finlayson, E.; Hopkins, D. A review of electrochromic window performance factors. In Proceedings of the SPIE International Symposium on Optical Materials Technology for Energy Efficiency and Solar Energy Conversion XIII, Friedrichsbau, Freiburg, Germany, 18-22 April 1994.

38. Piccolo, A.; Simone, F. Effect of switchable glazing on discomfort glare from windows. Build. Environ. 2009, 44, 1171-1180. [CrossRef]

39. Marmaras, N.; Nathanail, D. Introduction to Ergonomics; Hellenic Academic Libraries Link: Athens, Greek, 2015; Available online: http://hdl.handle.net/11419/513 (accessed on 1 March 2020).

40. Boverket. Boverket's Mandatory Provisions and General Recommendations, BBR, BFS 2011:6 with Amendments up to BFS 2018:4; Boverket: Karlskrona, Sweden, 2019.

(C) 2020 by the authors. Licensee MDPI, Basel, Switzerland. This article is an open access article distributed under the terms and conditions of the Creative Commons Attribution (CC BY) license (http://creativecommons.org/licenses/by/4.0/). 